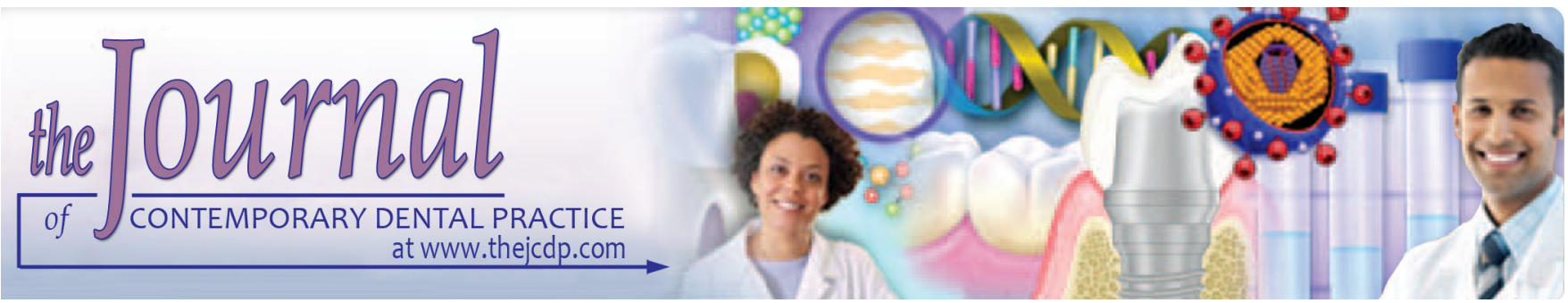

\title{
Clinical and Histopathological Analysis of Odontogenic Tumors in Institution-A 10 Years Retrospective Study
}

\author{
${ }^{1}$ Rajiv Mehngi, ${ }^{2}$ Kamala Rajendra, ${ }^{3}$ Pooja Bhagwat, ${ }^{4}$ Shruthi S Hegde, ${ }^{5}$ Divya Sah, ${ }^{6}$ Vikram S Rathod
}

\begin{abstract}
Aim: The present study was conducted to analyze the clinical and histopathological cases of odontogenic tumors (OTs).

Materials and methods: The present 10-year retrospective study comprised of 104 OTs. Parameters such as name, age, gender, clinical features, location, extension, etc were noted. $\mathrm{H}$ and $\mathrm{E}$ stained slides were carefully assessed by an oral pathologist and were classified according to the latest WHO classification of head and neck tumors.
\end{abstract}

Results: Out of 104 OTs, the most common was ameloblastoma constituting 45 cases, KCOT (28), odontoma (17), odontogenic myxoma (4), Calcifying epithelial odontogenic tumor (CEOT) (5), cementoblastoma (3) and calcifying cystic odontogenic tumor (2). The $p$ value found to be 0.01 (significant). Common OTs was ameloblastoma ( 25 males and 20 males), KCOT (12 males and 16 females), odontoma (10 males and 7 females), odontogenic myxoma ( 3 males and 1 female), CEOT ( 3 males and 2 females), cementoblastoma ( 2 males and 1 female) and calcifying cystic odontogenic tumor ( 1 male and 1 female). Ameloblastoma, $\mathrm{KCOT}$, and odontoma were predominantly seen in the age group 21-30 years, CEOT and cementoblastoma in age group

\footnotetext{
${ }^{1}$ Department of Oral Pathology, Government Hospital, Jammu, J\&K, India

${ }^{2}$ Department of Dentistry, Employees State Insurance Corporation Post Graduate Institute of Medical Science and Research, Rajajinagar, Bengaluru, Karnataka, India

${ }^{3}$ Department of Oral Pathology, College of Dental Sciences, Indore, Madhya Pradesh, India

${ }^{4}$ Department of Oral Medicine \& Radiology, Srinivas Institute of Dental Sciences, Mengaluru, Karnataka, India

${ }^{5}$ Department of Pedodontics, Triveni Dental College and Hospital, Bilaspur, Chattisgarh, India

${ }^{6}$ Department of Pedodontics, Vyas Dental College, Jodhpur, Rajasthan, India

Corresponding Author: Kamala Rajendra, Department of Dentistry, Employees State Insurance Corporation Post Graduate Institute of Medical Science and Research, Rajajinagar, Bengaluru, Karnataka, India, e-mail: anilkk44@ gmail.com
}

31-40 years. The difference was significant $(P<0.05)$. Common clinical features in OTs were facial disfigurement (65), swelling (78) and pain (55). The difference was non significant $(P$ $>0.05$ ). The average size of ameloblastoma was $6.8 \mathrm{~cm}$, KCOT was $4.2 \mathrm{~cm}$, odontoma was $3.9 \mathrm{~cm}$, odontogenic myxoma was $2.7 \mathrm{~cm}$, CEOT was $5.5 \mathrm{~cm}$, cementoblastoma was $3.8 \mathrm{~cm}$ and Calcifying cystic odontogenic tumour $(\mathrm{COC})$ was $3.6 \mathrm{~cm}$. The difference was non-significant $(p>0.05)$.

Conclusion: Mandible exhibited more OTs as compared to the maxilla. The most common lesion was ameloblastoma, KCOT, and odontomas. We observed male predominance.

Clinical significance: The study helps in assessing the occurrence of the odontogenic tumor. This is useful for identification and clinical management.

Keywords: Ameloblastoma, Keratocystic odontogenic tumor, Odontogenic tumor

How to cite this article: Mehngi $R$, Rajendra $K$, Bhagwat $P$, Hegde SS, Sah D, Rathod VS. Clinical and Histopathological Analysis of Odontogenic Tumors in Institution-A 10 Years Retrospective Study. The Journal of Contemporary Dental Practice, October 2018;19(10):1288-1292.

Source of support: Nil

Conflict of interest: None

\section{INTRODUCTION}

Odontogenic tumors (OTs) are those who arise in odontogenic tissues are a group of lesions occurring in the jaw bones. Epithelial and mesenchymal tissues are odontogenic tissues, and thus OTs involves epithelial or mesenchymal tissues. They constitute $1 \%$ of all tumors. ${ }^{1}$

A thorough knowledge of their clinical and histological features are mandatory in order to reach out the correct diagnosis. The clinician should be aware of the oral features, typical patterns, and location, etc. The pathologist should know characteristic features of each and every tumor so that the chances of confusion are eliminated. In this category, the most common is the ameloblastoma and keratocysticodontogenic tumor $(\mathrm{KCOT}){ }^{2}$ 
Over the past several modifications have been done in the classification of OTs. Recently in 2005, WHO included odontogenic keratocyst (OKC) in the classification of head and neck tumors. Earlier OKC was considered to be a cyst and now it has been mentioned as a benign tumor. Adebayo et al. ${ }^{3}$ reviewed 318 OTs in their study and found that ameloblastoma was the most commonly occurring lesion. Similarly, Tawfik et al. ${ }^{4}$ evaluated 82 odontogenic tumors in Dakahlia and concluded that among all tumors, ameloblastoma was the important one.

In a study by Santos et al. ${ }^{5}$ in Brazil, the prevalence rate of their occurrence was $2.4 \%$ out of 127 cases. Ledesma-Montes et al. ${ }^{6}$ in their regional Latin-American multicentric study reported $2.16 \%$ incidence rate.

Ameloblastoma is the benign tumor commonly occurs in the molar- ramus region of the mandible. The typical association with mandibular third molar has been observed by various authors. It has been considered anatomical benign in nature; and persistent clinically. It is multilocular in nature however, its unilocular variety does exists. ${ }^{7}$ The present study was conducted to analyze the clinical and histopathological cases of OTs reported to the department over the last 10 years.

\section{MATERIALS AND METHODS}

The present study was conducted jointly in two departments, the Department of Oral Medicine and Radiology and Department of Oral Pathology and Microbiology. After obtaining ethical clearance from the institutional ethical committee, the cases of odontogenic tumors visited the department of Oral Medicine and Radiology in the last 10 years (from 2006 to 2016) was selected. Inclusion criteria were all cases of OTs with clinical, radiographical and histological records. Cases with poor radiographs and insufficient tissue for biopsy were excluded from the study.

It comprised of 104 OTs. All OTs were primary except four recurrent cases of ameloblastoma. From their cases records, certain parameters such as name, age, gender, clinical features, location, extension, etc., was noted. Radiographs such as IOPAR and panoramic radiographs
Table 1: Distribution of cases

\begin{tabular}{|c|c|c|c|}
\hline \multicolumn{4}{|l|}{ Total-104 } \\
\hline Males & Females & \multicolumn{2}{|c|}{$p$-value } \\
\hline 56 & 48 & \multicolumn{2}{|c|}{0.1} \\
\hline \multicolumn{4}{|c|}{ Table 2: Occurrence of OTs } \\
\hline OTs & Nur & & $p$-value \\
\hline Ameloblastoma & 45 & $26 \%)$ & \\
\hline КСOT & 28 & $9 \%)$ & \\
\hline Odontoma & 17 & $3 \%)$ & 0.01 \\
\hline Odontogenic myxoma & & & \\
\hline $\begin{array}{l}\text { Calcifying epithe- } \\
\text { lial odontogenic tumor } \\
\text { (CEOT) }\end{array}$ & $5(4$ & & \\
\hline Cementoblastoma & $3(2$ & & \\
\hline $\begin{array}{l}\text { Calcifying cystic odon- } \\
\text { togenic tumor }\end{array}$ & & & \\
\hline
\end{tabular}

showing the extent of the lesions related to OTs were also retrieved from the departmental library. $\mathrm{H}$ and $\mathrm{E}$ stained slides were carefully assessed by two experienced oral pathologists for reconfirmation of the cases under a light microscope to overcome the observer bias.

All cases were classified according to the latest WHO classification of head and neck tumors. Data thus obtained were entered in Microsoft excel sheets. Descriptive statistics and logistic regression analysis were performed using Statistical Package for Social Sciences (SPSS) version 18. Odds ratios were used as measures of association between the independent and outcome variables. P-value less than 0.05 was considered significant.

\section{RESULTS}

Table 1 shows that out of 104 cases, 56 were in males and 48 were in females. The difference was non-significant (p-0.1). Table 2 shows that out of 104 OTs, the most common was ameloblastoma constituting 45 cases, KCOT (28), odontoma (17), odontogenic myxoma (4), Calcifying epithelial odontogenic tumor (CEOT) (5), cementoblastoma (3) and calcifying cystic odontogenic tumor (2). The Chi-square test was applied to find out the significant difference. The p-value found to be 0.01 (significant). Graph 1 shows that ameloblastoma was

Table 3: Age wise distribution of cases

\begin{tabular}{|c|c|c|c|c|c|c|c|c|}
\hline \multirow[b]{2}{*}{ OTs } & \multicolumn{8}{|c|}{ Age group } \\
\hline & $0-10$ & $11-20$ & $21-30$ & $31-40$ & $41-50$ & $51-60$ & $61-70$ & $p$-value \\
\hline Ameloblastoma & 2 & 8 & 12 & 10 & 7 & 4 & 2 & \\
\hline KCOT & 2 & 4 & 11 & 6 & 3 & 2 & 0 & \\
\hline Odontoma & 4 & 5 & 7 & 1 & 0 & 0 & 0 & \\
\hline Odontogenic myxoma & 1 & 0 & 1 & 1 & 1 & 0 & 0 & 0.01 \\
\hline $\begin{array}{l}\text { Calcifying epithelial odonto- } \\
\text { genic tumor }\end{array}$ & 0 & 0 & 2 & 3 & 0 & 0 & 0 & \\
\hline Cementoblastoma & 0 & 0 & 1 & 2 & 0 & 0 & 0 & \\
\hline $\begin{array}{l}\text { Calcifying cystic odontogenic } \\
\text { tumor }\end{array}$ & 0 & 1 & 0 & 0 & 0 & 0 & 1 & \\
\hline
\end{tabular}




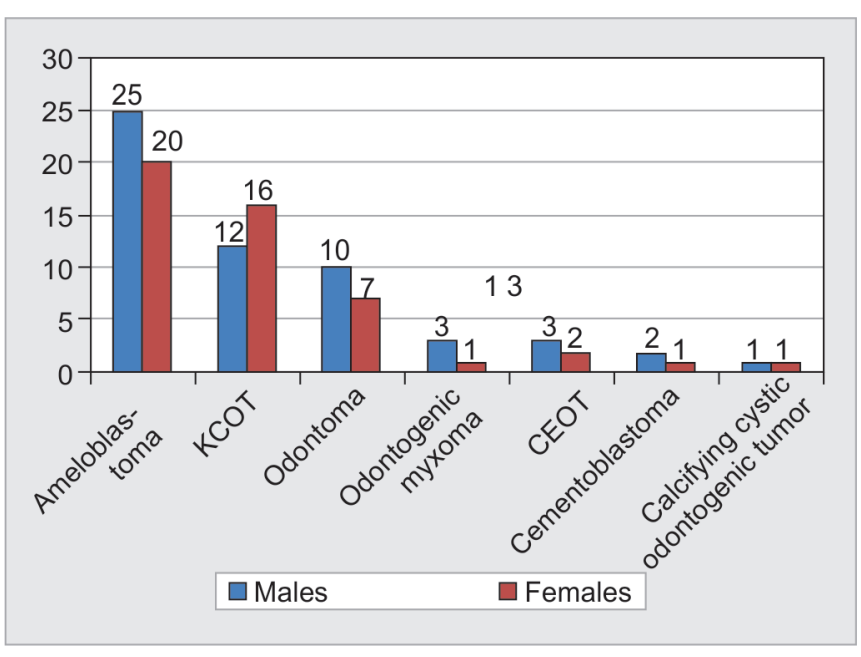

Graph 1: Gender wise distribution

seen in 25 males and 20 females, KCOT in 12 males and 16 females, odontoma in 10 males and 7 females, odontogenic myxoma in 3 males and 1 female, CEOT in 3 males and 2 females, cementoblastoma in 2 males and 1 females and calcifying cystic odontogenic tumor in 1 male and 1 female. Chi-square test revealed a significant difference $(\mathrm{p}<0.05)$. Table 3 shows that ameloblastoma was predominantly seen in the age group 21 to 30 years (12) followed by 31 to 40 years (10), 11 to 20 years (8), 41 to 50 years (7). KCOT was seen predominantly in the age group 21 to 30 years (11), odontoma was maximally seen in the age group 21 to 30 years, CEOT in the the age group

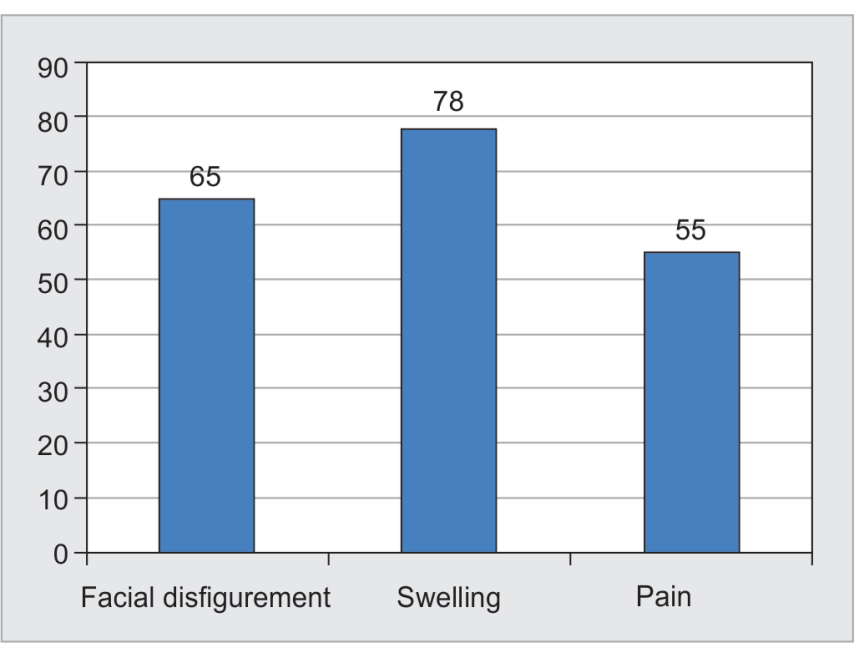

Graph 2: Clinical features in cases
31 to 40 years (3), cementoblastoma in the age group 31 to 40 years (2), odontogenic myxoma in age group 0 to 10 years (1), 21 to 30 years (1), 31 to 40 years (1) and 41 to 50 years (1). The calcifying cystic odontogenic tumor was observed in the age group 11 to 20 years (1) and 61 to 70 years (1). The difference was significant $(\mathrm{p}<0.05)$. Table 4 indicates the location of odontomes. Common location was mandibular posterior region. Graph 2 shows that common clinical features in OTs were facial disfigurement (65), swelling (78) and pain (55). The difference was non- significant ( $p>0.05)$. Graph 3 shows the mean size of OTs. Mean size of ameloblastoma was $6.8 \mathrm{~cm}$, KCOT $(4.2 \mathrm{~cm})$, odontoma $(3.9 \mathrm{~cm})$, odontogenic myxoma $(2.7 \mathrm{~cm})$, CEOT $(5.5 \mathrm{~cm})$, cementoblastoma (3.8 $\mathrm{cm})$ and $\mathrm{COC}(3.6 \mathrm{~cm})$. The difference was non-significant $(\mathrm{p}>0.05)$.

\section{DISCUSSION}

Odontogenic tumors are of paramount importance as these are responsible for facial disfigurement. Among various OTs, ameloblastoma is the commonly occurring entity. In the present study, the most commonly seen OT was ameloblastoma. We observed that ameloblastoma is present in $43.26 \%$ of present cases. Simon et al. in their study of odontogenic tumors and tumor-like lesions in the study population found that among various OTs, the occurrence of ameloblastoma was the maximum. A study by Vidya et al. ${ }^{8}$ found it to be $36.27 \%$. Francisco et al. ${ }^{9}$ conducted a study of clinic-pathological and demographic pattern and found that ameloblastoma was present in 70 cases.

We found that the second commonly found lesion was KCOT. In the present study, it was seen in $26.9 \%$ (28) of all cases. KCOT or OKC is a benign entity is one of the OT. The occurrence of tumor-like properties has put it in the classification of head and neck tumors by WHO in the year 2005. The peculiar thing about this tumor is that it has the tendency of recurrence due to remnants of satellite cysts. Ataolah et al. ${ }^{10}$ in the year 2007 conducted a 10-year retrospective study in which the author found 83 cases of the keratocystic odontogenic tumor. Osterne et al. ${ }^{11}$ in their 5 -year retrospective study in a Brazilian population assessed 3406 cases and found that KCOT is

Tables 4: Location of OTs

\begin{tabular}{lcccc}
\hline \multicolumn{1}{c}{ OTs } & Post mand. & Ant mand. & Post max. & Ant max. \\
\hline Ameloblastoma & 32 & 8 & 4 & 1 \\
KCOT & 24 & 2 & 2 & 0 \\
Odontoma & 6 & 5 & 4 & 2 \\
Odontogenic myxoma & 3 & 0 & 0 & 1 \\
Calcifying epithelial odontogenic tumor & 3 & 2 & 0 & 0 \\
Cementoblastoma & 3 & 0 & 0 & 0 \\
Calcifying cystic odontogenic tumor & 0 & 0 & 0 & 2 \\
\hline
\end{tabular}




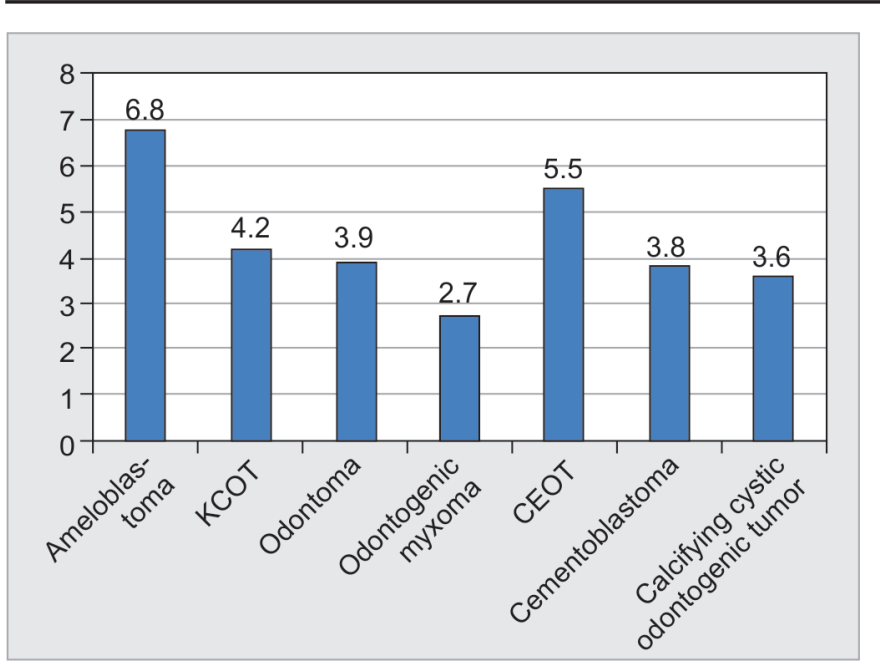

Graph 3: Mean size of OTs

present in $28 \%$ of all OTs. Avelar et al. ${ }^{12}$ clinically and pathologically studied 238 odontogenic tumors and found $36 \%$ of occurrence of the keratocystic odontogenic tumor. The important feature of this tumor was the destructive nature which demands attention.

We found odontoma in 17 cases. 5 out of $17 \mathrm{had}$ aggressive nature. Seo- young $(2012)^{13}$ analyzed 72 cases of odontoma. These are also known as hemartomas due to its slow growth. However, these are best called OTs. It comprises $22 \%$ of all Odontogenic tumors. Jing et al. ${ }^{14}$ studied 1642 cases of Odontogenic tumors in Chinese population and found Odontome in $17 \%$ of the study population.

We observed calcifying epithelial odontogenic tumor in 5 cases of all OTs. This is in agreement with the study by Olgac et al. ${ }^{15}$ Similarly odontogenic myxoma $(3.8 \%)$, cementoblastoma $(2.8 \%)$ and calcifying cystic odontogenic tumor $(1.9 \%)$ was seen in less quantity.

We found that there was a male predominance of occurrence of OTs. Our results are in accordance to study by Grasieli et al. ${ }^{16}$ who analyzed OTs in a 14-year retrospective study. The author found OT in 32 males as compared to 31 females. However, the difference between genders was not too much. Similarly, in the present study, OTs was seen in 56 males and 48 females. However, Mendes et al. in their 156 cases of epithelial OTs, female occurrence were observed in 88 cases whereas male lesions were seen in 68 cases. Sriram et al. ${ }^{17}$ in 2008 evaluated 158 OTs and found 1.6:1 male: female ratio. We observed that ameloblastoma was seen predominantly in the age group 21-30 years followed by age group 31 to 40 (10) and 11 to 20 (8). This is in agreement with the study by Eh-Gihani et al. ${ }^{18}$ KCOT (11) and odontoma (7) was predominantly seen in the age group 21 to 30 .

The occurrence of ameloblastoma and KCOT was in posterior mandible in more than $80 \%$ of cases. We found that ameloblastoma was seen 32 cases out of 45 in the posterior mandible. Similarly, KCOT was seen in the posterior mandible in 24 cases. Saghravanian et al. ${ }^{19}$ in their 30-year evaluation of odontogenic tumors in an Iranian population also found similar results. Guerrisi et al. ${ }^{20}$ in the 15 -year retrospective study of odontogenic tumors in children and adolescents in Argentina found that the occurrence of most of the OTs was in posterior mandible in molar- ramus area. Bruktawit et al. ${ }^{21}$ conducted an 8-year retrospective study of OTs in Ethiopia and found that $77.3 \%$ of Odontogenic tumors were occurring in mandible as compared to maxilla (22.3\%). Authors found males predominance (163) as compared to females (75). Da Costa ${ }^{22}$ conducted a study on 349 cases of Odontogenic tumors in Mexico. It was a retrospective study and most of the OTs were located in the mandible. All the cases were aggressive in nature.

In the present study, we found that 65 patients had complaints of facial disfigurement, 78 cases of swelling and 55 cases had pain. In study by Bruktawit et al., ${ }^{21}$ the patients had complaints of malocclusion and continuity defect. Buchner ${ }^{23}$ analyzed 127 cases and found that common symptoms in patients were swelling, disfigurement whereas Okada found swelling in $45.8 \%$ of cases. ${ }^{24}$

\section{CONCLUSION}

Odontogenic tumors exhibit unique clinical features. The location of OTs follows a uniform pattern throughout the world. The most common lesion was ameloblastoma, $\mathrm{KCOT}$, and odontomas. We observed male predominance. Mandible exhibited numbers of OTs as compared to the maxilla.

\section{CLINICAL SIGNIFICANCE}

The present study provides valuable information on the patient demographic details, the clinical presentations and histopathological presentation of odontogenic tumours. The data from the study could be used to establish odontogenic tumour profiles among the study population

\section{REFERENCES}

1. Luo HY, Li TJ. Odontogenic tumors: a study of 1,309 cases in Chinese population. Oral Oncology 2009;45:706-711.

2. Kim SG, Jang HS. Ameloblastoma: A clinical, radiographic and histopathologic analysis of 71 cases. Oral Surg Oral Med Oral Pathol Oral RadiolEndod 2001;91:649-653.

3. Adebayo, E. T.; Ajike, S. O. and Adekeye, E. O. A review of 318 odontogenic tumors in Kaduna, Nigeria. J. Oral Maxillofac. Surg. 2005;63(6):811-819.

4. Tawfik, M. A. and Zyada, M. M. Odontogenic tumors in Dakahlia, Egypt: analysis of 82 cases. Oral Surg. Oral 
Med. Oral Pathol Oral Radiol Endod 2010;109(2): 67-73.

5. Santos JN, Pereira Pinto L, Figueredo CRLV, Souza LB. Odontogenic tumors: analysis of 127 cases. PesquiOdont Bras 2001;15:308-313.

6. Ledesma-Montes C, Mosqueda-Taylor A, Carlos-Bregni R, de Leon ER, Palma-Guzman JM, Perez-Valencia C, et al. Ameloblastomas: a regional Latin-American multicentric study. Oral Dis 2007;13(3):303-307.

7. Olaitan AA, Adeola DS, Adekeye EO. Ameloblastoma: clinical features and management of 315 cases from Kaduna, Nigeria. J Craniomaxillofac Surg 1993;21:351-355.

8. Vidya Kadashetty et al. Odontogenic tumors- A retrospective study of 102 cases. IJOCR 2014;2(1):7-11.

9. Francisco et al. Clinicopathological and demographic characteristics of ameloblastomas in a population from Bahia, Brazil. Rev. Odontoscienc. 2010;25(3):250-255.

10. Atoalah Habibi et al. KeratocysticOdontogenic tumors- A 10 years retrospective study of 83 cases in an Iranina population J Oral scie. 2007;(49)3:229-235.

11. Osterne RL, Brito RG, Alves AP, Cavalcante RB, Sousa FB.Odontogenic tumors: a 5-year retrospective study in a Brazilian population and analysis of 3406 cases reported in the literature. Oral Surg Oral Med Oral Pathol Oral RadiolEndod 2011;111(4):474-481.

12. Avelar RL, Antunes AA, Santos TS, Andrade ES, Dourado E. Odontogenic tumors: clinical and pathology study of 238 cases. Braz J Otorhinolaryngol. 2008;74(5):668-673.

13. Seo-Young An, Chang-Hyeon An, Karp-ShikChoi. Odontoma: a retrospective study of 73 cases. Imaging Science in Dentistry 2012;42:77-81.

14. Jing $\mathrm{W}$, Xuan $\mathrm{M}$, Lin $\mathrm{Y}, \mathrm{Wu} \mathrm{L}$, Liu L, Zheng $\mathrm{X}$, et al. Odontogenictumours: a retrospective study of 1642 cases in a Chinese population. Int J Oral MaxillofacSurg 2007; 36(1):2025.
15. Olgac V, Koseoglu BG, Aksakalli N. Odontogenictumours in Istanbul: 527 cases. Br J Oral MaxillofacSurg 2006; 44(5):386388.

16. Grasieli de Oliveira Ramos et al. Odontogenic tumors: a 14-year retrospective study in Santa Catarina, Brazil. Braz Oral Res. 2014;28(1):1-6.

17. Sriram G, Shetty RP. Odontogenic tumors: a study of 250 cases in an Indian teaching hospital. Oral Surg Oral Med Oral Pathol Oral RadiolEndod 2008;105:14-21.

18. El-Gehani, R.; Orafi, M.; Elarbi, M. andSubhashraj, K. Benign tumours of orofacial region at Benghazi, Libya: a study of 405 cases. J. Craniomaxillofac. Surg., 2009;37(7): 370-375.

19. Saghravanian N, Jafarzadeh $\mathrm{H}$, Bashardoost N, Pahlavan N, Shirinbak I. Odontogenic tumors in an Iranian population: a 30-year evaluation. J Oral Sci 2010;52(3):391-396.

20. Guerrisi M, Piloni MJ, Keszler A. Odontogenic tumors in children and adolescents. A 15-year retrospective study in Argentina. Med Oral Patol Oral Cir Bucal 2007;12(3): 180-185.

21. Bruktawit et al. Odontogenic tumors in Ethiopia: eight years retrospective study. BMC Oral Health 2017;17: 54.

22. da Costa D-O-P, Mauricio A-S, de Faria P-A-S, da Silva L-E, Mosqueda-Taylor A, Lourenco S-Q-C. Odontogenic tumors: a retrospective study of four Brazilian diagnostic pathology centers. Med Oral Patol Oral Cir Bucal 2012;17:389394.

23. Buchner A, Merrell PW, Carpenter WM. Relative frequency of 23. Peripheral odontogenic tumors: a study of 45 new cases and comparison with studies from the literature. J Oral Pathol Med 2006;35:385-391.

24. Okada, H.; Yamamoto, H. and Tilakaratne W. M. Odontogenic tumors in Sri Lanka: analysis of 226 cases. J. Oral Maxillofac. Surg 2007; 65(5):875-882. 